\title{
ANALISIS PRODUKTIVITAS METODE PELAKSANAAN PENGECORAN BETON READY MIX PADA BALOK DAN PELAT LANTAI GEDUNG
}

\author{
Ariany Frederika ${ }^{1}$ dan Ida Ayu Rai Widhiawati ${ }^{1}$
}

\begin{abstract}
Abstrak : Penggunaan teknologi metoda pelaksanaan konstruksi beton pada gedung bertingkat mengalami perkembangan yang signifikan, baik dari pengolahan bahan campuran beton maupun peralatan pengecorannya. Beberapa peralatan pengecoran diantaranya lift cor dan Concrete pump, keduanya menghasilkan produktivitas yang berbeda, sehingga berpengaruh terhadap waktu dan biaya pelaksanaan. Penelitian ini bertujuan untuk menganalisis produktivitas peralatan pengecoran, menganalisis biaya dan waktu, serta titik impas metode pelaksanaan pengecoran beton ready mix pada balok dan pelat lantai gedung bertingkat, khususnya pada lantai II, III dan IV menggunakan Lift Cor dan Concrete pump. Data diperoleh dengan wawancara dan observasi pelaksanaan pengecoran dari proyek konstruksi g e d u ng yang menggunakan beton ready mix dengan mutu K-300. Metoda analisis Regresi dan Korelasi digunakan untuk memperoleh perbandingan biaya dan waktu pelaksanaan pengecoran, serta analisis Break Even Point untuk mendapatkan titik impas volume pengecoran terhadap biaya dan waktu pelaksanaan. Hasil analisis menunjukkan produktivitas pengecoran menggunakan lift cor pada lantai II, III, dan IV sebesar 7,166 m3/jam, 5,945 m3/jam, 5,125 m3/jam; dengan concrete pump untuk lantai II, III, dan IV sebesar $36 \mathrm{~m} 3 / \mathrm{jam}, 30 \mathrm{~m} 3 / \mathrm{jam}, 24 \mathrm{~m} 3 / \mathrm{jam}$. Perbandingan biaya tiap pertambahan $1 \mathrm{~m} 3$ pengecoran menggunakan LC dan CP sebesar Rp. 99.330 : Rp.19.000 (5,23 : 1), dan perbandingan waktu sebesar $(8,272: 2,172)$ menit atau $(3,8: 1)$. Titik impas volume terhadap biaya pengecoran menunjukkan bahwa pada Lt. II dengan volume lebih besar dari 95,89 m3 pengecoran lebih optimal menggunakan concrete pump.
\end{abstract}

Kata kunci: metode pengecoran, produktivitas, lift cor, concrete pump, regresi, titik impas

\section{PRODUCTIVITY AND BREAK EVEN POINT ANALYSIS OF READY MIX CASTING METHOD ON THE BEAMS FLOOR SLABS OF STOREY BUILDINGS}

\begin{abstract}
Implementation method technology of multi-storey building concrete construction is experiencing significant growth, both in material processing and casting equipment. Several casting equipment including concrete lift and concrete pump have different productivities which contribute to time and cost. This research aims to analyze the productivity of casting equipment, time and cost required, as well as the break-even point of casting method of ready mix concrete application on the beams and the floor slabs of buildings, particularly on the second- floor, third- floor and forth-floor using concrete lift and concrete pump. Data was obtained by conducting interviews and observations concerning casting implementation of building construction projects that use K-300 ready- mix concrete. Regression and Correlation analysis are used to obtain time and cost comparison between both method of casting implementation, as well as Break Even Point analysis to obtain breakeven point of casting volume with regards to cost and time. The analysis showed that casting productivities using lift on first, second and third floor are $7,166 \mathrm{~m}^{3} / \mathrm{h}, 5,945 \mathrm{~m}^{3} / \mathrm{h}, 5,125 \mathrm{~m}^{3} / \mathrm{h}$, while the productivities using concrete pump on first, second and third floor are $36 \mathrm{~m}^{3} / \mathrm{h}, 30 \mathrm{~m}^{3} / \mathrm{h}, 24 \mathrm{~m}^{3} /$ hour. Cost comparison of $1 \mathrm{~m}^{3}$ increment of casting using concrete lift and concrete pump is Rp. 99 330: Rp.19.000 (5.23: 1), while time ratio is 8.272 minutes: 2,172 minutes (3.8: 1). Breakeven point analysis towards casting cost showed that the second floor which has volume greater than $95.89 \mathrm{~m} 3$, using concrete pump method is more optimal than concrete-lift.
\end{abstract}

Keywords: casting method, productivity, concrete lift, concrete pump, regression analysis, breakeven point

\footnotetext{
${ }^{1}$ Staf Pengajar Program Studi Teknik Sipil, Fakultas Teknik, Universitas Udayana, Denpasar.

Corresponding email: arianyfrederika1@yahoo.com
} 


\section{PENDAHULUAN}

Teknologi pelaksanaan proyek konstruksi beton pada gedung bertingkat mengalami perkembangan yang signifikan, baik dari pengolahan bahan campurannya sampai pada tahap pengerjaannya, salah satunya pada metode menggunakan peralatan pengecoran beton. Peralatan yang ada harus disesuaikan dengan ketinggian bangunan tersebut, disamping memperhatikan keadaan di lapangan maupun pertimbangan-pertimbangan lain dari kontraktor. Salah satu komponen struktur gedung bertingkat yang menggunakan beton dan memiliki volume yang besar ialah konstruksi balok dan pelat lantai.

Beton merupakan campuran agregat halus, agregat kasar, semen, dan air dengan atau tanpa bahan tambahan lainnya (Murdock,1999). Pengadukan beton secara masinal ada dua yaitu beton site mix yang diproduksi dengan concrete mixer (molen) pada lokasi proyek dan beton ready mix (siap pakai) diproduksi pada perusahaan batching plant di luar proyek. Dalam pelaksanaan pengecoran beton secara konvensional pada gedung bertingkat yang menggunakan beton siap pakai (ready mix), ada beberapa peralatan pengecoran yang digunakan seperti lift cor dan concrete pump. Lift cor adalah alat untuk memindahkan beton secara vertikal dengan menggunakan bucket. Concrete pump adalah alat yang berupa pipa atau selang yang dapat dipasang kombinasi vertikal dan horisontal atau miring untuk memompa dan menyalurkan beton.

Setiap peralatan pengecoran yang digunakan menghasilkan produktivitas yang berbeda- beda sehingga berpengaruh terhadap lamanya waktu pengecoran dan sangat erat kaitannya dengan biaya yang akan dikeluarkan dalam penyelesaian proyek. Pilihan menggunakan peralatan pengecoran yang tepat tentu akan menguntungkan kontraktor. Untuk mendapatkan acuan dalam menyelesaikan pekerjaan pengecoran, maka perlu dianalisis produktivitasnya agar dapat diperkirakan biaya dan waktu pelaksanaan yang optimal. Sehingga penelitian ini bertujuan untuk:

1. Untuk menganalisis produktivitas pengecoran beton ready mix menggunakan peralatan lift cor dan concrete pump pada balok dan pelat lantai gedung

2. Untuk menganalisis perbandingan biaya dan waktu pelaksanaan metode pengecoran beton ready mix menggunakan peralatan lift cor dan concrete pump.

3. Untuk menganalisis titik impas volume terhadap biaya dan waktu masing-masing peralatan pengecoran beton ready mix pada balok dan pelat lantai gedung

\section{PENGECORAN BETON}

Beton merupakan campuran antara agregat halus, agregat kasar, semen portland atau semen hidraulik yang lain, dan air, dengan atau tanpa bahan additive (tambahan) sebagai percepatan pemadatan (SNI 03-2847-2002). Pengecoran beton pada balok dan pelat lantai dapat dilaksanakan setelah struktur kolom selesai dikerjakan, dilanjutkan dengan pemasangan perancah dan bekisting, penulangan balok dan pelat lantai, kemudian dilanjutkan dengan pengecoran beton. Proses pengecoran beton dimulai saat beton plastis dituangkan ke dalam cetakan baik menggunakan bucket (dibantu dengan alat berat) maupun melalui pipa. Beton yang sudah dituang ke area pengecoran kemudian dikonsolidasikan dan diratakan. Konsolidasi dilakukan bertujuan untuk mengurangi rongga dalam beton, dapat dilakukan secara manual dengan cara merojok menggunakan besi batang atau sekop, dan dapat dilakukan dengan alat penggetar (vibrator).

\section{Beton Ready Mix (Siap Pakai)}

Beton ready mix menurut Nilson, dkk. (2008) adalah beton yang pencampuran materialnya dibuat di lokasi batching plan, kemudian beton ready mix dalam bentuk beton segar diangkut menggunakan truk mixer ke lokasi proyek. Penggunaan beton ready mix pada konstruksi bangunan sangat menguntungkan dibandingkan dengan beton yang diproduksi sendiri, terutama jika dipergunakan dalam volume yang besar dan pada konstruksi pracetak. Keuntungan ini didapat dari waktu yang seharusnya dipergunakan untuk proses pembuatan beton dapat dihilangkan sehingga pekerjaan hanya dibutuhkan saat proses pengecoran beton, selain itu proses pencampuran tertentu dapat tercapai dan mutu beton yang diharapkan dapat terpenuhi.

Beton ready mix dapat disiapkan dengan beberapa jalan, yaitu (Peurifoy et al.,1996):

Central-mixed concrete,
pencampuran material beton sepenuhnya dilakukan dalam suatu mixer dan diangkut ke proyek dengan menggunakan truk molen.

2. Shrink-mixed concrete, dimana setengah pencampuran material beton dilakukan di dalam suatu mixer kemudian dimasukkan dalam truk mixer dan pencampuran selanjutnya dilakukan dalam perjalanan ke lokasi proyek.

3. Truck-mixed concrete, dimana pencampuran material beton sepenuhnya di dalam truk mixer, dengan 70 sampai 100 putaran pada suatu kecepatan yang cukup untuk mencampur beton. Beton jenis ini umumnya disebut "transit mixer concrete" karena dicampur dalam perjalanan. 
Truk mixer merupakan alat yang digunakan untuk membawa campuran beton segar dari pabrik pembuatan ready mix (batching plan) ke lokasi proyek dengan sistem bak yang terus berputar dengan kecepatan yang sudah diatur sedemikian rupa supaya campuran beton selama dalam perjalanan tidak berkurang kualitasnya.

\section{Peralatan Pengecoran}

Secara umum jenis peralatan pengecoran yang digunakan dalam pelaksanaan pengecoran di lapangan yaitu lift cor dan concrete pump. Masing - masing memiliki spesifikasi, produktifitas dan teknis pengecoran yang berbeda beda.

1. Lift Cor adalah alat yang digunakan untuk mengangkut campuran beton secara vertikal, dilengkapi bucket dengan penggerak mesin diesel untuk mengalirkan menuju area yang dicor dengan lintasan terbuka (talang), dibuat sesuai kebutuhan di lapangan. Lift ini terdiri dari tiang-tiang baja yang disusun secara vertikal sesuai ketinggian yang diinginkan. Panjang masing-masing tiang baja berbedabeda yaitu, panjang tiang pertama $4,5 \mathrm{~m}$, tiang kedua 3,5 $\mathrm{m}$, tiang ketiga dan seterusnya memiliki panjang $3 \mathrm{~m}$. Tiang baja pertama dijadikan s e baga i pondasi lift, ditanam kurang lebih 1 meter. Tiang-tiang lift juga diperkuat dengan besi pengait ke struktur bangunan. Lift ini dilengkapi dengan bucket yang digunakan untuk menampung adukan beton, kapasitas bucket yang digunakan adalah $0,2 \mathrm{~m} 3$. Bucket ini ditarik kawat baja yang digerakkan oleh mesin diesel berdaya $20 \mathrm{Pk}$.

2. Concrete Pump adalah alat yang dapat dipasang kombinasi vertikal dan horisontal atau miring, untuk menyalurkan bahan cor beton melalui saluran tertutup (pipa/selang) dengan pemompaan ke tempat pengecoran (Rochmanhadi, 1992). Agar pompa dapat bekerja dengan baik, pengecoran harus dilakukan dengan konsisten dan waktu pelaksanaan yang seragam. Pompa tersedia dalam berbagai ukuran, dimana pompa dapat mengirimkan beton dari 8 sampai $115 \mathrm{~m} 3$ per jam. Pemompaan yang efektif antara 90 - 300 meter horizontal, atau 30 - 90 meter vertikal, namun pompa jenis tertentu dapat memindahkan beton sampai 1500 meter horizontal dan 300 meter vertikal. Produksi aktual tergantung dari beberapa hal, antara lain: tipe pompa yang dipakai, ukuran pipa pengecor, dan efisiensi operasi.

\section{Produktivitas Peralatan}

Produktivitas adalah perbandingan antara output dan input hasil yang didapat (output) dengan seluruh sumber daya yang digunakan (input). Produktivitas alat tergantung pada kapasitas dan waktu siklus alat. Rumus dasar untuk mencari produktivitas alat adalah (Rostiyanti, 2008):

Produktifitas $=\frac{\text { kapasitas }}{\mathrm{CT}}$

atau

Produktifitas $=\frac{\text { volume pekerjaan }}{\text { durasi }}$

Jika faktor efisiensi alat dimasukan maka rumus menjadi :

Produktifitas $=$ kapasitas $\mathrm{x} \frac{60}{\mathrm{CT}} \mathrm{x}$ efisensi

Keterangan:

Produktifitas alat dihitung dalam $\mathrm{m}^{3} / \mathrm{jam}$, waktu alat ditetapkan dalam menit (60 menit)

kapasitas = kapasitas bucket untuk menampung beton dalam $\mathrm{m}^{3}$

CT $=$ cyclus time / waktu siklus (menit)

efisiensi = waktu efektif alat bekerja dalam satu jam (menit/jam)

Siklus kerja pemindahan material merupakan suatu kegiatan yang dilakukan berulang. Pekerjaan utama dalam kegiatan tersebut adalah memuat, memindahkan, membongkar muatan dan kembali ke kegiatan awal. Semua kegiatan itu dapat dilakukan oleh satu alat atau beberapa alat. Waktu yang diperlukan dalam melakukan kegiatan tersebut disebut waktu siklus atau cycle time (CT), dirumuskan sebagai berikut (Rostiyanti, 2008):

$\mathrm{CT}=\mathrm{LT}+\mathrm{HT}+\mathrm{DT}+\mathrm{RT}+\mathrm{ST}$

Keterangan:

a. Waktu muat atau loading time (LT), yaitu waktu yang dibutuhkan alat untuk memuat material ke dalam alat angkut sesuai kapasitasnya.

b. Waktu angkut atau hauling time (HT), yaitu waktu yang diperlukan alat untuk bergerak dari tempat pemuatan ke tempat pembongkaran material.

c. Waktu pembongkaran atau dumping time (DT), yaitu waktu yang diperlukan alat untuk pembongkaran material di tempat yang ditentukan.

d. Waktu kembali atau return time (RT), yaitu waktu yang diperlukan alat untuk kembali ke tempat pemuatan.

e. Waktu tunggu atau spotting time (ST), yaitu waktu alat menunggu sampai alat diisi embali. 
Faktor efisiensi alat sangat mempengaruhi produktivitas, dimana efisiensi alat tersebut bekerja tergantung dari beberapa hal yaitu :

1. Kemampuan operator pemakai alat

2. Pemilihan dan pemeliharaan alat

3. Perencanaan dan pengaturan letak alat

4. Topografi dan volume pekerjaan

5. Kondisi cuaca

6. Metode pelaksanaan alat

Dalam menentukan besarnya efisiensi kerja alat di lapangan memang sulit, namun berdasarkan pengalaman dapat ditentukan efisiensi yang mendekati kenyataan, seperti tabel 1 (Rochmanhadi, 1984).

Tabel 1. Efisiensi Kerja

\begin{tabular}{cccccc}
\hline Kondisi & \multicolumn{5}{c}{ Pemeliharaan Mesin } \\
\cline { 2 - 6 } $\begin{array}{c}\text { Operasi } \\
\text { Alat }\end{array}$ & $\begin{array}{c}\text { Baik } \\
\text { Sekali }\end{array}$ & Baik & Sedang & Buruk & $\begin{array}{c}\text { Buruk } \\
\text { Sekali }\end{array}$ \\
\hline Baik Sekali & 0,83 & 0,81 & 0,76 & 0,70 & 0,63 \\
\hline Baik & 0,78 & 0,75 & 0,71 & 0,65 & 0,60 \\
\hline Sedang & 0,72 & 0,69 & 0,65 & 0,60 & 0,54 \\
\hline Buruk & 0,63 & 0,61 & 0,57 & 0,52 & 0,45 \\
\hline Buruk Sekali & 0,52 & 0,50 & 0,47 & 0,42 & 0,32 \\
\hline Sumber: Rochmanhadi (1984)
\end{tabular}

\section{Analisis Biaya dan Waktu Pelaksanaan}

Pada dasarnya setiap pembangunan tidak terlepas dari kecermatan seorang pelaksana untuk merancang suatu metode kerja yang efisien. Metode kerja yang efisien sangat berpengaruh pada biaya yang diperlukan untuk melakukan pekerjaan tersebut. Selain metode, peralatan yang digunakan juga harus diperhatikan, karena akan berpengaruh terhadap biaya dan waktu pelaksanaan. Menurut Soedradjat (1994), dalam menentukan harga satuan analisis didasarkan pada 5 komponen biaya, yaitu biaya bahan/material, tenaga kerja, peralatan, biaya tak terduga (overhead), dan keuntungan (profit).

\section{Biaya Material}

Untuk menaksir biaya material dibuat suatu daftar bahan yang menjelaskan mengenai banyaknya, ukuran, berat dan ukuran lain yang diperlukan. Harga bahan yang dipakai merupakan harga bahan di tempat pekerjaan, sudah termasuk biaya angkutan, menaikkan dan menurunkan.

\section{Upah Tenaga Kerja}

Produktivitas tenaga kerja adalah kemampuan menghasilkan suatu unit produksi dalam satuan waktu tertentu dari tenaga kerja. Jumlah tenaga kerja yang dibutuhkan dapat ditentukan dengan diketahuinya beberapa variabel seperti volume pekerjaan, durasi, produktivitas, sehingga biaya upah tenaga kerja dapat dihitung

\section{Biaya Peralatan}

Peralatan yang diperlukan untuk suatu jenis pekerjaan konstruksi, didalamnya harus termasuk bangunan-bangunan sementara, mesin-mesin dan alat-alat manual. Peralatan ini bisa merupakan peralatan milik sendiri maupun sewa dari pihak lain. Perhitungan analisis biaya peralatan dapat dibagi dalam dua kategori, yaitu biaya kepemilikan alat dan biaya pengoperasian alat

4. Biaya Tak Terduga

Biaya tak terduga dimaksudkan untuk mengurangi resiko-resiko yang terjadi akibat suatu hal diluar perkiraan dan perencanaan, misalnya kenaikan harga bahan, upah, sewa alat dan sebagainya. Jumlah biaya tak terduga dapat ditentukan secara langsung dengan membandingkan jumlah biaya total.

\section{Keuntungan}

\section{Analisis Regresi dan Korelasi}

Regresi dan korelasi digunakan untuk mempelajari pola dan mengukur hubungan statistik antara dua atau lebih variabel, jika digunakan hanya dua variabel disebut regresi dan korelasi sederhana dan jika digunakan lebih dari dua variabel disebut regresi dan korelasi berganda (Wirawan, 2012). Menurut Dajan (2008) analisis regresi adalah analisis yang dapat mengubah suatu data menjadi suatu fungsi. Dengan analisis ini bisa mengubah data-data dari survey atau eksperimen di lapangan menjadi suatu fungsi matematik. Data tersebut terdiri dari 2 kelompok dan dapat diperoleh dari berbagai bidang kegiatan yang menghasilkan pasangan observasi atau pengukuran sebanyak $n$ yang dinyatakan sebagai $\left(\mathrm{X}_{\mathrm{i}}, \mathrm{Y}_{\mathrm{i}}\right)$ di mana $\mathrm{i}=1,2, \ldots, \mathrm{n}$.

Hubungan fungsional (sebab-akibat) antara variabel bebas $(\mathrm{X})$ dan variabel terikat $(\mathrm{Y})$ dalam bentuk fungsi dinyatakan sebagai $\mathrm{Y}=\mathrm{f}(\mathrm{x})$, yang artinya nilai variabel $\mathrm{Y}$ tergantung dari atau dipengaruhi oleh nilai variabel X. Sifat hubungan antara variabel bebas (X) dengan variabel terikat (Y), dapat positif, negatif atau tidak ada hubungan. Hubungan positif yang juga disebut hubungan searah, artinya bila nilai $\mathrm{X}$ naik maka nilai $\mathrm{Y}$ juga naik atau sebaliknya bila nilai $X$ turun maka nilai $Y$ juga turun. Hubungan negatif disebut juga hubungan berlawanan arah, artinya bila nilai $\mathrm{X}$ naik maka nilai $\mathrm{Y}$ akan turun atau sebaliknya bila nilai $X$ turun maka nilai $Y$ akan naik. Tidak ada hubungan, artinya bila nilai $\mathrm{X}$ berubah (naik/turun), maka nilai Y tidak akan berubah (tetap). Bila ketiga jenis sifat hubungan antara dua variabel tersebut dinyatakan dalam grafik, bentuk grafiknya seperti pada Gambar 1. 


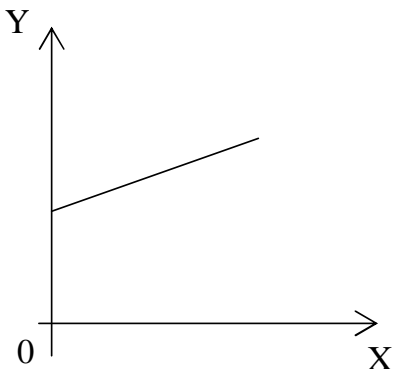

(a) Hubungan positif

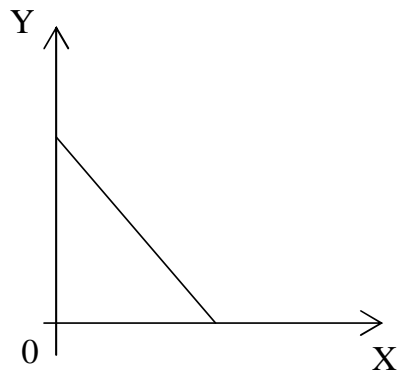

(b) Hubungan negatif

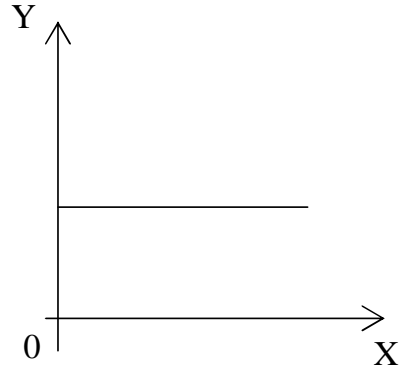

(c) Tidak ada hubungan

Gambar 1. Tiga Grafik yang menyatakan hubungan variabel X dan Y Sumber: Wirawan (2012)

\section{Analisis Regresi Linier Sederhana}

Secara umum persamaan garis regresi linier sederhana dinyatakan sbb:

$$
Y=a+b X
$$

Rumus persamaan regresi tersebut diperoleh dengan menggunakan Metode Kuadrat Terkecil (Least Squares Method). Apabila diberikan serangkaian data sampel $\left(\mathrm{X}_{\mathrm{i}}, \mathrm{Y}_{\mathrm{i}}\right)$ dengan $\mathrm{i}=1,2,3$ .... n, maka nilai dugaan (peramalan) kuadrat terkecil bagi parameter dalam persamaan garis regresi dinyatakan sebagai berikut (Wirawan, 2012):

$$
\hat{\mathrm{Y}}=\mathrm{a}+\mathrm{bX}
$$

Metode kuadrat terkecil akan memberikan jumlah kuadrat deviasi vertikal (tegak) dari titik titik observasi ke garis regresi tersebut sekecil mungkin, atau dengan kata lain metode kuadrat terkecil memberikan $\Sigma\left(\mathrm{Y}_{\mathrm{i}}-\hat{\mathrm{Y}}\right)^{2}=\sum\left(\mathrm{e}_{\mathrm{i}}\right)^{2}$ yang terkecil. Hal tersebut dapat dilihat pada Gambar 2 mengenai kriteria kuadrat terkecil.

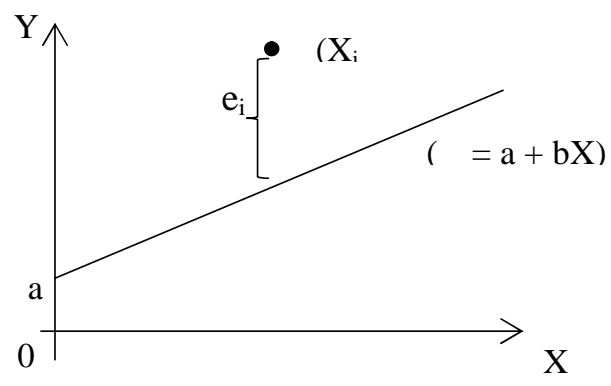

\section{Gambar 2 Kriteria Kuadrat Terkecil Sumber: Wirawan (2012)}

Agar jumlah kuadrat simpangan vertikal ke garis regresi yaitu $\sum\left(\mathrm{Y}_{\mathrm{i}}-\hat{\mathrm{Y}}\right)^{2}$ sekecil mungkin, maka $\Sigma\left(\mathrm{Y}_{\mathrm{i}}-\hat{\mathrm{Y}}\right)^{2}=\Sigma\left(\mathrm{e}_{\mathrm{i}}\right)^{2}$ diminimumkan terhadap a dan b. Untuk menentukan nilai a dan b diberikan dengan rumus sebagai berikut:

$$
\begin{aligned}
& b=\frac{n \sum X Y-\sum X \sum Y}{n \sum X^{2}-\left(\sum X\right)^{2}} \\
& a=\frac{\left(\sum Y-b \sum X\right)}{n}
\end{aligned}
$$

Keterangan:

$\hat{\mathrm{Y}}=$ Taksiran nilai $\mathrm{Y}$

$\mathrm{X}=$ Variabel bebas (data pengamatan)

$\mathrm{Y}=$ Variabel terikat (data pengamatan)

$\mathrm{a}=$ konstanta atau titik potong dengan sumbu $\mathrm{Y}$, bila $\mathrm{X}=0$

$\mathrm{b}=$ arah garis regresi, yang menyatakan perubahan nilai $\mathrm{Y}$ akibat perubahan 1 unit $\mathrm{X}$

$\mathrm{n}$ = banyaknya pasangan data observasi/ pengukuran

Nilai koefisien regresi bisa bertanda positif atau negatif, hal teresebut menyatakan arah hubungan atau pengaruh variabel bebas $\mathrm{X}$ terhadap variabel terikat $Y$. Interpretasi terhadap nilai koefisien regresi (b) adalah sebagai berikut:

- $b=A$ ( $b$ bertanda positif), artinya bila nilai variabel bebas $X$ naik/bertambah 1 unit, maka nilai variabel $\mathrm{Y}$ naik/bertambah sebesar 1 unit. Sebaliknya bila nilai variabel bebas $\mathrm{X}$ turun/berkurang 1 unit, maka nilai variabel $\mathrm{Y}$ turun/berkurang sebesar 1 unit.

- $\mathrm{b}=-\mathrm{A}$ ( $\mathrm{b}$ bertanda negatif), artinya bila nilai variabel bebas $X$ naik/bertambah 1 unit, maka nilai variabel $\mathrm{Y}$ akan turun/berkurang sebesar 1 unit. Sebaliknya bila nilai variabel bebas $X$ turun/berkurang 1 unit, maka nilai variabel $\mathrm{Y}$ akan naik/bertambah sebesar 1 unit.

\section{Analisis Korelasi Sederhana}

Analisis korelasi bertujuan untuk mengetahui keeratan hubungan (kuat-lemahnya) hubungan antara variabel bebas $\mathrm{X}$ dengan variabel terikat $\mathrm{Y}$, tanpa melihat bentuk hubungannya, apakah linier atau tan-linier. Kuat-lemahnya hubungan antara dua variabel dilihat dari koefisien korelasinya. Koefisien korelasi linier (r) adalah ukuran hubungan linier antara dua variabel/peubah acak X 
dan Y untuk mengukur sejauh mana titik-titik menggerombol sekitar sebuah garis lurus regresi. Sedangkan koefisien determinasi ( $\left.r^{2}\right)$ merupakan alat untuk mengukur ketepatan garis regresi terhadap sebaran datanya. Rumusan untuk koefisien korelasi ada dua, yaitu: Analisis korelasi biasanya dilakukan secara bersamaan dengan analisis regresi. Jika analisis korelasi dilakukan secara bersamaan dengan analisis regresi, maka koefisien korelasi merupakan akar dari koefsien determinasi, yang dapat dihitung dengan rumus sebagai berikut:

$$
\begin{aligned}
& r=\sqrt{r^{2}} \\
& r=\sqrt{\frac{a \sum Y_{i}+b \sum X_{i} Y_{i}-\mathrm{n}(\bar{Y})^{2}}{\sum Y_{i}^{2}-\mathrm{n}(\bar{Y})^{2}}} \\
& r=\frac{n \sum X_{i} Y_{i}-\sum X_{i} \sum Y_{i}}{\sqrt{n \sum X_{i}^{2}-\left(\sum X_{i}\right)^{2}} \sqrt{n \sum Y_{i}^{2}-\left(\sum Y_{i}\right)^{2}}}
\end{aligned}
$$

\section{Titik Impas (Break Even Point / BEP)}

Break Even Point (BEP) memiliki pengertian yang sama dengan kata-kata titik impas, tidak rugitidak untung atau seimbang (Soehardi, 1995). Menurut Nugraha (1985), break event point adalah suatu keadaan tertentu (titik), dimana keadaan netral, tidak untung dan tidak rugi atau keadaan dimana suatu alternatif tidak lebih baik ataupun tidak lebih jelek dari alternatif yang lainnya. Sebaliknya dikatakan bahwa di atas atau di bawah titik tersebut, keadaan adalah jelek atau baik, alternatif A lebih baik dari alternatif B, dan sebagainya.

Penggunaan analisis BEP dapat digunakan untuk mengetahui titik impas, dari pengecoran beton ready mix pada balok dan pelat lantai gedung mengunakan peralatan yang satu dengan yang lainnya. Dalam analisis BEP ini, dicari perpotongan dari persamaan garis regresi dari masing-masing peralatan pengecoran. Perpotongan dari persamaan garis yang dapat digunakan adalah metode eliminasi, yaitu dengan cara mengalikan dengan sebuah angka sehingga ada variabel yang mempunyai koefisien yang sama.

\section{METODE PENELITIAN}

\section{Survei dan Tabulasi Data}

Survei dilakukan pada dua proyek dengan ketinggian bangunan yang sama yaitu Proyek Pembangunan Hotel Santika untuk metoda pengecoran dengan Lift cor yang berlokasi di Seminyak, Badung dan Proyek Pembangunan Hotel Avani Nusa Dua Circle untuk metode pengecoran dengan Concrete Pump. Data primer yang dicari dari wawancara dan observasi (pengamatan langsung) di lapangan yaitu jumlah tenaga kerja dan peralatan yang dibutuhkan, kapasitas alat dan volume pekerjaan serta waktu kerja alat dan tenaga kerja saat proses pengecoran, sedangkan data sekunder berupa gambar struktur bangunan, upah tenaga kerja, biaya sewa dan jenis peralatan yang digunakan (lift cor dan concrete pump).

\section{Perhitungan waktu siklus}

Hasil observasi dilapangan ditabulasi dan dihitung sehingga diperoleh waktu siklus pengecoran dengan Lift cor dan Concrete pump. Rekapitulasi rata-rata waktu siklus terdapat pada tabel 2 dan 3 sebagai berikut:

Tabel 2 Rekapitulasi Data Rata-Rata Waktu Siklus Lift Cor

\begin{tabular}{|c|c|c|c|c|c|c|c|c|}
\hline $\begin{array}{c}\text { Rata- } \\
\text { Rata }\end{array}$ & \multicolumn{5}{|c|}{ Waktu Siklus (detik) } & $\begin{array}{c}\text { Total } \\
\text { Waktu } \\
\text { (dtk) }\end{array}$ & \multicolumn{2}{|c|}{ Per 6 m3 } \\
\cline { 1 - 4 } Lantai & LT & HT & DT & RT & ST & & (dtk) & (menit) \\
\hline II & 30.140 & 9.990 & 20.210 & 5.010 & 10.000 & 75.350 & 2486.550 & 41.443 \\
III & 30.220 & 20.245 & 20.548 & 9.846 & 10.000 & 90.859 & 2998.347 & 49.972 \\
IV & 30.189 & 29.914 & 20.333 & 14.917 & 10.000 & 105.353 & 3476.649 & 57.944 \\
\hline
\end{tabular}

\begin{tabular}{|c|c|c|c|c|c|c|}
\hline Rata-rata & \multicolumn{5}{|c|}{ Waktu Siklus (detik) } & Total \\
\hline Lantai & LT & HT & DT & RT & ST & $\begin{array}{c}\text { waktu } \\
\text { (dtk) }\end{array}$ \\
\hline II & 0.810 & 0 & 4.260 & 0 & 5 & 10.070 \\
\hline III & 0.920 & 0 & 5.690 & 0 & 5 & 12.010 \\
\hline IV & 1.420 & 0 & 8.450 & 0 & 5 & 14.870 \\
\hline
\end{tabular}

Tabel 3 Rekapitulasi Data Rata-Rata Waktu Siklus Concrete pump

Sumber: hasil survey (2015)

\section{HASIL DAN PEMBAHASAN}

Berdasarkan perhitungan produktivitas diperoleh perbandingan biaya dan waktu, kemudian dianalisis regresi dan korelasi untuk mendapatkan perbandingan dan titik impas biaya dan waktu masing - masing peralatan pengecoran tiap lantainya. Analisis regresi bertujuan untuk mendapatkan persamaan garis fungsi dari data pengamatan waktu dan perhitungan biaya, sehingga bisa digunakan dalam menaksir perhitungan biaya dan waktu pengecoran dalam volume tertentu. Selain itu persamaan garis tersebut dapat digunakan dalam perhitungan titik impas (break even point) antara peralatan yang satu dengan yang lainnya. Analisis korelasi bertujuan untuk mengetahui kuat 
lemahnya hubungan antara biaya dan waktu terhadap volume pengecoran.

\section{Produktivitas dan koefisien tenaga kerja Lift} Cor

Pengecoran Balok dan Pelat Lantai II

Volume pekerjaan $=6 \mathrm{~m}^{3}$

Durasi pengamatan $=41,443$ menit

Waktu siklus $\quad=75,351$ detik $=1,256$ menit

Jumlah tenaga kerja (Mandor + Pekerja)

$$
=1+10=11 \text { orang }
$$

Prod. alat $=$ kapasitas $x \frac{60}{\mathrm{CT}} \times$ efisiensi

$$
\begin{aligned}
& =0,2 \times \frac{60}{1,256} \times 0,75 \\
& =7,166 \mathrm{~m} 3 / \mathrm{jam}
\end{aligned}
$$

Prod. tenaga kerja $=$ prod. alat $=7,166 \mathrm{~m}^{3} / \mathrm{jam}$

Selanjutnya, perhitungan untuk lantai III dan IV dapat dilihat di Tabel 4.

\begin{tabular}{|c|c|c|c|c|c|c|c|c|}
\hline \multirow{3}{*}{ Lantai } & \multicolumn{2}{|c|}{ Jumiah TKeria } & \multirow{2}{*}{\begin{tabular}{|c|} 
Produktivitas Ts \\
(M/Jam) \\
\end{tabular}} & \multicolumn{2}{|c|}{ Koefisien TK } & \multicolumn{2}{|l|}{ Upah } & \multirow{2}{*}{$\begin{array}{c}\text { Total Upah } \\
\text { (R) }\end{array}$} \\
\hline & Mandor & pekerja & & Mancior & Pekerja & Nandor & Pekeria & \\
\hline & $\Lambda$ & $b$ & $c$ & $d-3 / e$ & $e-b / c$ & 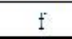 & $g$ & $\mathrm{~b}-\left(\mathrm{d}^{4} \mathrm{t}\right)+\left(\mathrm{e}^{*}\right.$ \\
\hline II & : & 10 & 1.166 & 0.1392 & 1.393 & 3,000 & 10,000 & $66,235.21$ \\
\hline III & : & 10 & 5.915 & 0.1682 & 1.682 & 75,000 & 10,000 & $79,899.07$ \\
\hline IV & : & 10 & 5.125 & 0.1051 & 1.251 & 75,000 & 40,000 & $22,682.93$ \\
\hline
\end{tabular}

Tabel 4 Produktivitas, dan Upah $\left(1 \mathrm{~m}^{3}\right.$ /jam $)$ pengecoran dengan Lift cor

\section{Produktivitas dan koefisien tenaga kerja dengan}

\section{Concrete Pump (CP)}

Pengecoran balok dan plat lantai II

$$
\begin{aligned}
\text { Volume pekerjaan } & =6 \mathrm{~m}^{3} \\
\text { Durasi pengamatan } & =10,07 \text { menit } \\
\text { Jumlah tenaga kerja } & =\text { Mandor }+ \text { Pekerja } \\
& =1+12 \\
& =13 \text { orang }
\end{aligned}
$$

\begin{tabular}{|c|c|c|c|c|c|c|c|c|}
\hline \multirow{3}{*}{ Lantai: } & \multicolumn{2}{|c|}{ Inll Tetraga Karga } & \multirow{2}{*}{$\begin{array}{l}\text { Frodultivititas } \\
\mathrm{IK} \text { (m3 } \mathrm{j} \mathrm{jam})\end{array}$} & \multicolumn{2}{|c|}{ bocef tnnaga kreja } & \multicolumn{2}{|c|}{ Hargen Eatuan (Rp) } & \multirow{2}{*}{ Total Lpul (R\&) } \\
\hline & Mendor & Poberja & & Yartor & Pakeria & Mancior & Pakaria & \\
\hline & Á & $\bar{b}$ & $\bar{c}$ & $i=\mathrm{d}^{2}$ & $e=\mathrm{de}$ & 1 & G & $1=\left(d^{x} I\right)+\left(u^{*} w\right)$ \\
\hline$\pi$ & 1 & 12 & 36 & 0.0278 & 0.3333 & 75.000 & 40.000 & $15.500,00$ \\
\hline III & 1 & 12 & 30 & 0.0333 & 0.4 & 75.000 & 40.000 & $18.500,00$ \\
\hline N & 1 & 12 & 24 & 0.0416 & 0.5 & 75.000 & 40.000 & $23.075,00$ \\
\hline
\end{tabular}

Produktifitas alat dan tenga kerja (grup)

$$
=\frac{\text { volume }}{\text { durasi }}=\frac{6}{10,07}=0,6 \mathrm{~m}^{3} / \mathrm{menit}=36 \mathrm{~m}^{3} / \mathrm{jam}
$$

Selengkapnya produktivitas dan upah pengecoran dengan CP dirangkum pada tabel 5.

Tabel 5 Produktivitas dan Upah $\left(1 \mathrm{~m}^{3} / \mathrm{jam}\right)$ pengecoran dengan concrete pump

\section{Hasil Analisis Regresi dan Korelasi}

Dari hasil pada tabel 4 kemudian dianalisis regresi dan korelasi menggunakan persamaan 5 sampai persamaan 11 untuk setiap kelipatan $6 \mathrm{~m} 3$ pengecoran masing-masing peralatan pengecoran dan diperoleh persamaan masing-masing seperti

\begin{tabular}{|c|c|c|}
\hline \multirow{2}{*}{$\begin{array}{l}\text { Tingkat } \\
\text { Lantai }\end{array}$} & LIFT COR & CONCRETE PUMP \\
\hline & $\begin{array}{c}\text { Pers. Regresi ( } \hat{Y}=a+ \\
\text { bX ) } \\
\text { Nilai a dan b (jam) }\end{array}$ & $\begin{array}{l}\text { Pers. Regresi }(\hat{Y}=a+b X) \\
\quad \text { Nilai a dan } b(j a m)\end{array}$ \\
\hline II & $\hat{Y}=0,0023+0,1152 X$ & $\hat{Y}=0,0173+0,0309 X$ \\
\hline III & $\hat{Y}=0,0079+0,1382 X$ & $\hat{Y}=0,2660+0,0362 X$ \\
\hline IV & $\hat{Y}=0,0156+0,1602 X$ & $\hat{\mathrm{Y}}=0,5175+0,0415 X$ \\
\hline
\end{tabular}
pada Tabel 6 dan Tabel 7.

\begin{tabular}{|c|c|c|}
\hline \multirow{2}{*}{$\begin{array}{c}\text { Tingkat } \\
\text { Lantai }\end{array}$} & $\begin{array}{c}\text { LIF COR } \\
(\hat{\mathrm{Y}}=\mathrm{a}+\mathrm{bX})\end{array}$ & $\begin{array}{c}\text { CONCRETE PUMP } \\
(\hat{\mathrm{Y}}=\mathrm{a}+\mathrm{bX})\end{array}$ \\
\hline II & $\hat{\mathrm{Y}}=0,4775+0,0749 \mathrm{X}$ & $\hat{\mathrm{Y}}=3,8+0,0154 \mathrm{X}$ \\
\hline III & $\hat{\mathrm{Y}}=0,6229+0,0962 \mathrm{X}$ & $\hat{\mathrm{Y}}=3,8+0,0185 \mathrm{X}$ \\
\hline IV & $\hat{\mathrm{Y}}=0,9553+0,1269 X$ & $\hat{\mathrm{Y}}=3,8+0,0231 X$ \\
\hline
\end{tabular}

Rata-rata Biaya dengan LC:

$$
\hat{Y}=0,68523+0,09933 X
$$

Rata-rata Biaya dengan CP:

$$
\hat{\mathrm{Y}}=3,8+0,019 \mathrm{X}
$$

Tabel 7 Rekapitulasi persamaan regresi waktu Lift Cor dan Concrete Pump

Rata-rata waktu dengan LP:

$$
\hat{\mathrm{Y}}=0,0086+0,13787 \mathrm{X}
$$

Rata-rata waktu dengan CP:

$$
\hat{\mathrm{Y}}=0,26693+0,0362 \mathrm{X}
$$

Titik impas waktu antara lift cor dan concrete pump

Koordinat titik impas lift cor dengan concrete pump. Contoh perhitungan titik impas pada Lantai II, untuk eliminasi ' $\hat{Y}$ ' :

LC: $\hat{\mathrm{Y}}=0,0023+0,1152 X \rightarrow 0,1152 X=-0,0023$

$\mathrm{CP}: \hat{\mathrm{Y}}=0,0173+0,0310 X \rightarrow 0,0310 X=-0,0173$ 
Dikurangi:

$$
\begin{aligned}
0,0842 X & =0,0150 \\
X & =0,1782
\end{aligned}
$$

Masukkan nilai ' $\mathrm{X}$ ' ke rumus $\mathrm{LC}$ :

$$
\mathrm{y}=0,0023+0,1152(0,1782)=0,0228
$$

Jadi antara LC dan CP bertitik impas di titik

$$
\mathrm{x}=0,1782 \text { dan } \mathrm{y}=0,0228 \text { (Grafik } 1)
$$

Grafik 1. Titik Impas Waktu LC dan CP Lantai 2

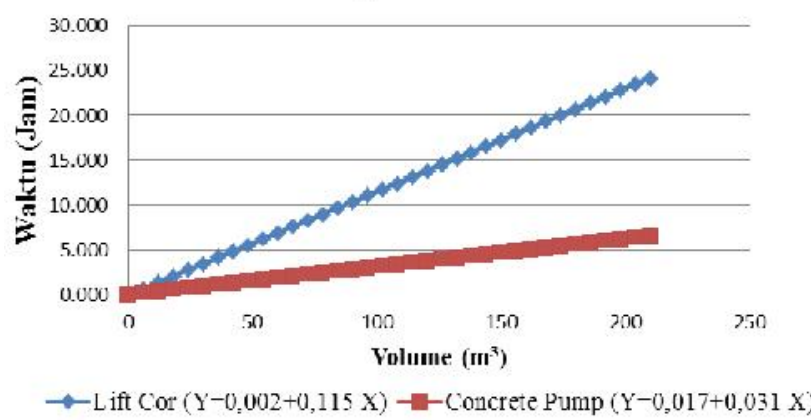

Titik impas volume terhadap waktu pada lantai $2(0,1782 \mathrm{~m} 3 ; 0,0228$ jam $)$ dan volume terhadap biaya $(95,8937 \mathrm{~m} 3$; Rp 4.661.700,00) menunjukkan bahwa pada Lt. II dengan volume lebih besar dari 95,89 m3 pengecoran lebih optimal (lebih cepat waktunya dan biaya lebih rendah) dengan menggunakan concrete pump. Selengkapnya titik impas volume terhadap biaya dan waktu ditampilkan pada Tabel 8.

Tabel 8

Titik Impas volume terhadap biaya dan waktu

\begin{tabular}{|c|c|r|c|c|}
\hline \multirow{2}{*}{ Tingkat } & \multicolumn{4}{|c|}{ Titik Impas LC dan CP } \\
\cline { 2 - 5 } Lantai & \multicolumn{2}{|c|}{ Volume dan Biaya } & \multicolumn{1}{c|}{ Volume dan Waktu } \\
\cline { 2 - 5 } & $\mathrm{X}(\mathrm{m} 3)$ & Y(juta) & X (m3) & Y (jam) \\
\hline II & 95.8937 & 4.661 & 0.1782 & 0.0228 \\
III & 40.393 & 4.556 & 2.5299 & 0.3576 \\
IV & 27.407 & 4.432 & 4.2278 & 0.6928 \\
\hline
\end{tabular}

\section{SIMPULAN DAN SARAN}

\section{Simpulan}

1. Produktivitas pengecoran beton ready mix menggunakan peralatan lift cor pada lantai II, III, dan IV sebesar 7,166 m3/jam, 5,945 $\mathrm{m} 3 / \mathrm{jam}, 5,125 \mathrm{~m} 3 / \mathrm{jam}$; dengan concrete pump untuk lantai II, III, dan IV sebesar 36 m3/jam, 30 m3/jam, 24 m3/jam.

2. Perbandingan biaya tiap pertambahan $1 \mathrm{~m} 3$ pengecoran menggunakan LC dan CP sebesar Rp. 99.330 : Rp.19.000 (5,23 : 1), dan perbandingan waktu sebesar $(8,272: 2,172)$ menit atau $(3,8: 1)$.

3. Titik impas volume terhadap biaya pengecoran pada lantai II, III, dan IV adalah
(95,8937 m3 ; Rp 4.661.700,00); (40,393 m3; Rp. 4.556.500,00); (27,407 m3; Rp. 4.432.400,00); Titik Impas volume terhadap waktu pengecoran pada lantai II, III, dan IV adalah: (0,1782 m3; 0,0228 jam); (2,5299 m3; $0,3576$ jam $) ;(4,2278 \mathrm{~m} 3 ; 0,6928$ jam $)$.

\section{Saran}

1. Kontraktor agar mempertimbangkan pemilihan alat pengecoran sesuai dengan tinggi tingkat gedung yang akan dicor, demikian juga waktu dan biaya pelaksanaannya,karena peralatan yang ada memiliki jangkauan ketinggian berbeda-beda.

2. Selain biaya dan waktu yang berkaitan erat dengan produktifitas peralatan pengecoran, perlu juga diperhitungkan perbandingan mutu beton yang dihasilkan oleh peralatan sebelum dan sesudah pengecoran beton ready mix, serta pengaruh mutu beton yang digunakan terhadap produktifitas peralatan pengecoran.

\section{DAFTAR PUSTAKA}

Murdock, L. J., Brook, K. M., Hindarko, S., 1999. Bahan dan Praktek Beton. Erlangga, Jakarta.

Peurifory, R. L., Ledbetter, W. B., Schexnayder, C. V. 1996. Construction Planing Equipment and Method, $5^{\text {th }}$ Edition McGraw-Hill.

Rochmanhadi. 1985. Perhitungan Biaya Pelaksanaan Pekerjaan dengan Menggunakan Alat-alat Berat. Badan Penerbit Pekerjaan Umum, Jakarta.

Rostiyanti, S. F. 2008. Alat Berat Untuk Proyek Konstruksi. Rineka Cipta, Jakarta

Soehardi, S. 1995. Analisa Break Even Point, Ancangan Linear Secara Ringkas dan Praktis. BPFE, Yogyakarta.

Soedradjat, A. 1994. Analisa Anggaran Biaya Pelaksanaan. Nova, Bandung.

Wirawan, N. 2012. Statistika Ekonomi dan Bisnis (Statistik Deskriptip). Keraras Emas, Denpasar. 